\title{
Seroprevalence of Brucellosis among General Population in Famenin City, Western Iran in 2016: The Famenin Brucellosis Cohort Study
}

\author{
Fariba Keramat, MD, PhD'; Manoochehr Karami, PhD ${ }^{2,3}$; Mohammad Yousef Alikhani, PhD'; Saeid Bashirian, PhD ${ }^{4}$; Abbas Moghimbeigi, \\ PhD ${ }^{1,5}$; Seyyed Hamid Hashemi, MD, PhD'; Mojgan Mamani, MD, PhD'; Zahra Shivapoor, MSc ${ }^{4}$; Mile Bosilkovski, MD, PhD ${ }^{1,6}$; Maryam \\ Adabi, $\mathrm{PhD}^{1^{*}}$
}

${ }^{1}$ Brucellosis Research Center, Hamadan University of Medical Sciences, Hamadan, Iran ${ }^{2}$ Research Center for Health Sciences, Hamadan University of Medical Sciences, Hamadan, Iran ${ }^{3}$ Department of Epidemiology, School of Public Health, Hamadan University of Medical Sciences, Hamadan, Iran ${ }^{4}$ Social Determinants of Health Research Center, Hamadan University of Medical Sciences, Hamadan, Iran ${ }^{5}$ Department of Biostatistics and Epidemiology, School of Health, Alborz University of Medical Sciences, Karaj, Iran ${ }^{6}$ University Hospital for Infectious Diseases and Febrile Conditions, Medical Faculty, Skopje, Republic of Macedonia

\begin{abstract}
Background: Brucellosis is endemic in Iran with a higher level of endemicity in western areas, including the Hamadan province. This study aims to define the seroprevalence of brucellosis and it,s risk factors in general the population of Famenin, Hamadan province, in western Iran.

Methods: This survey was conducted on 2367 participants in Famenin and its villages from September to November 2016. After receiving written consent from subjects, demographic information was obtained through questionnaires and 10cc blood samples were taken from the participants. Blood samples were sent to the Core facility of Hamadan University of Medical Sciences and were tested using Wright and 2ME kits (Pasteur Institute, Iran) for serological detection of brucellosis. The seroprevalence of brucellosis was reported as percentage with 95\% confidence interval $(\mathrm{Cl})$.

Results: Totally, 2367 individuals with the mean age (SD) of 34.6 (20.9) (range: 2 to 95) years were enrolled. Of these, 1060 $(44.8 \%)$ were men and $1610(68.0 \%)$ lived in rural areas. The seroprevalence of brucellosis according to the Wright titer (equal to or greater than $1: 80)$ was $6.6 \%(95 \% \mathrm{Cl}: 5.62 \%, 7.66 \%)$. The corresponding prevalence based on $2 \mathrm{ME}$ titers (equal to or greater than $1: 40)$ in subjects with positive Wright test was $37.2 \%(95 \% \mathrm{Cl}: 29.5 \%, 44.84 \%)$. We saw a significant association between the incidence of brucellosis and occupation $(P<0.001)$ and type of contact with livestock $(P=0.009)$ as two important risk factors. Conclusion: The seroprevalence of brucellosis in Famenin population was considerable. Contact with livestock, animal husbandry, farming and history of brucellosis were risk factors for brucellosis infection.

Keywords: Brucellosis, Famenin, Iran, Seroprevalence, Zoonotic infectious disease

Cite this article as: Keramat F, Karami M, Alikhani MY, Bashirian S, Moghimbeigi A, Hashemi SH, et al. Seroprevalence of brucellosis among general population in Famenin city, Western Iran in 2016: The Famenin Brucellosis Cohort Study. Arch Iran Med. 2020;23(11):749-756. doi: 10.34172/aim.2020.99.
\end{abstract}

Received: December 11, 2019, Accepted: September 6, 2020, ePublished: November 1, 2020

\section{Introduction}

Brucellosis is a common bacterial disease in both humans and animals, which is transmitted through unsafe contact with infected animals or consuming contaminated dairy products. In brucellosis, we encounter a range of clinical manifestations from asymptomatic infection to severe forms. ${ }^{1}$ Brucella is a gram-negative coccobacillus without spores and capsules with at least four species that have been pathogenic for humans; Brucella abortus, Brucella suis, Brucella melitensis and Brucella canis. ${ }^{2}$ The role of phagocytosis and cellular immunity in brucellosis immune response have been demonstrated. ${ }^{2}$ Brucella involves various organs and can exhibit non-specific symptoms such as weakness, bone pain, fever, muscle aches, weight loss, sweating and headache. ${ }^{2,3}$
In Iran, brucellosis is an endemic disease with $B$. melitensis as the most common pathogen. The incidence of brucellosis is high in some provinces of Iran such as Lorestan, Kermanshah and Hamadan., ${ }^{4,5}$ Hamadan, with incidence rates of 31.7 per 100000 population in 2008, 36.7 per 100000 population in 2010 , as well as $62.9,81.4$ and 91.0 per 100000 population in the years 2012, 2013, and 2014, respectively, was among the provinces with the highest prevalence of brucellosis. ${ }^{4,6}$ Administrative reports from national and provincial notifiable diseases surveillance systems indicated that the incidence rate of brucellosis in Iran was 21 per 100000 population, while in Hamadan, it was approximately three times the rate of national occurrence in 2012. The corresponding incidence rate per 100000 population in Famenin was 105 in 2014. 
In areas where brucellosis is endemic, there are many undiagnosed patients with asymptomatic exist who are not diagnosed and fewer than 10\% are detected after an infection in primary phases. ${ }^{7,8}$

The diagnosis of brucellosis is usually confirmed by Brucella isolation from blood or bone marrow or by demonstrating rising antibody titers to Brucella antigens in blood samples. Numerous serological tests are used for detection of brucellosis. ${ }^{3}$ In our country, Wright and 2ME tests are routinely used for establishing the diagnosis. ${ }^{9-11}$

Our aim in this study was to assess the brucellosis seroprevalence and the most important risk factors for brucellosis infection in order to define effective strategies for control and reduction of brucellosis in the general population of Famenin (a city in the province of Hamadan).

\section{Material and Methods}

Study Design and Sampling Method

This study was carried out on the general population of Famenin and its surrounding villages during a threemonth period (September to November 2016) .

The number of samples was calculated using the following formula.

$$
n=\frac{z_{1-\frac{\alpha}{2}}^{2}(p)(1-p)}{(d)^{2}}
$$

Considering the prevalence rate of brucellosis, with 20\% of people having Wright's test titers between 1:20 and $1: 5120$ in the region $(P=0.20)$, we considered $\mathrm{z}=1.96$ (for $\alpha=0.05$ ) and $d$ (absolute error) $=0.018$. Finally, the sample size was calculated at 1898 ; by applying a design effect equal to 1.25 , the required blood sample size was calculated at 2371 .

The cluster sampling method was used after classification of the Famenin population based on urban and rural areas of residence. The urban population of Famenin in 2016 was $17979(-42 \%)$ while the rural population was 25065 $(-58 \%)$. The total clusters were selected proportional to the urban and rural population. Each cluster included 10 households or 40 people. So based on this, 1440 people (36 clusters) in villages and 960 people (24 clusters) in cities were calculated.

To select the head of the clusters, the first and last postal code of each division was first obtained from the post office. Based on the aggregation of the postal codes, the mentioned clusters were proportional to the density of the postal codes of each division. Large divisions with more households accounted for a greater fraction of the sample size. Then, using systematic sampling considering each category sample size, the postal codes of head clusters from rural and urban areas were selected and sampling in each cluster was performed consecutively from the first postal code and continuing to include 40 people or 10 households. The questionnaire was administered to the any household head of cluster, and continued to reach 10 households or 40 individuals (preferably at least 40 in 10 households). Using this systematic approach, we achieved a geographically representative distribution of eligible clusters. The address of the head of clusters was obtained from the post office to dispatch the questionnaire and collect data. To select a random number to start systematic sampling, Excel software was used. If the postal code did not belong to a home, the nearest postal code would be replaced. In case of absence of a household, the questionnaire was completed twice within 24 hours with on-site presence and on the third referral (second followup), by giving a special form of referral to neighbors; to invite the family members for questioning and sampling. If a member of the household wished to participate in the study, the interviewer completed the questionnaire with informed consent, regardless of the non-cooperation of the other household members. If the household did not cooperate, the interviewer continued by completing the questionnaire for the next household. All subjects of the urban and rural population of Famenin entered the study between September to November 2016. Individuals younger than two years were not included in the study. According to the cluster sampling, households in Famenin were determined by coding the areas and households.

Data Gathering

After receiving written consent, health workers in the area asked each participant about the maximal data relating to brucellosis including sex (male, female), pregnancy (yes, no), marital status (married, single), education (illiterate, elementary, middle school, high school, diploma, superdiploma and higher), residence (city, village), occupation (animal husbandry farmer, housewife, other), history of brucellosis (yes, no), history of infection (yes, no), recurrence history among people with a history of infection (yes, no), number of relapses (among people with recurrence history), current treatment for brucellosis among people with a history of infection (yes, no), contact with livestock (yes, no), livestock species (cow, small ruminants), type of contact with the livestock (contact with aborted fetus, contact with live animals, contact with discharge after delivery, keeping livestock, slaughtering the livestock, contact with meat and organs, contact with carcasses and livestock secretions after slaughter, milking livestock), use of masks in people who have contact with the livestock (yes, no), using local dairy (yes, no), local dairy type (milk, skim milk, cheese, butter, cream curd, colostrum, traditional ice cream) and brucellosis infection in family members during the past two years (yes, no) which were entered into questionnaires by questioners.

\section{Diagnostic Test}

Brucellosis was considered in any subject with Wright test 
equal to or greater than 1:80 and a $2 \mathrm{ME}$ test equal to or greater than 1:40 with clinical symptoms consistent with brucellosis (fever, sweating, weight loss, loss of appetite and muscle or bone pain) or positive blood cultures. ${ }^{6}$ Brucellosis infection was defined by positive serology with or without clinical symptoms compatible with brucellosis. ${ }^{3}$ The sensitivity and specificity of Wright test based on previous studies were reported at $91.8 \%-100 \%$ and $63.6 \%-100 \%$, respectively. ${ }^{9,12-14}$ The sensitivity and specificity of $2 \mathrm{ME}$ was reported at $52 \%-93.7 \%$ and $75 \%-$ $100 \%$, respectively.,15 Wright and 2ME kits by Pasteur Institute of Iran were used to assess the seroprevalence of brucellosis. Ten cc blood samples were taken from each subject and sent to the core facility of Hamadan University of Medical Sciences (microbiology laboratory) for Wright and $2 \mathrm{ME}$ tests. $2 \mathrm{ME}$ tests were performed for those who had Wright titers equal to or greater than 1:40.

\section{Statistical Analysis}

After reviewing the questionnaires, we analyzed all data using SPSS software version 16 . Numerical variables were presented as mean and standard deviation and qualitative variables as frequency and percentages. The seroprevalence of brucellosis was reported as percentage with 95\% confidence interval. We used the chi-square test to investigate the relationships between qualitative variables. The comparison between quantitative variables in different groups was performed using $t$ test. Because of cluster sampling, to define the effective factors and risk factors for the occurrence of brucellosis and its prevalence, a mixed effect logistic regression model was used. In the mixed effect model, the estimation of standard error (confidence interval) of parameters adjusts because of cluster sampling. To fit the mixed effects logistic regression model and to determine the most important factors influencing Wright test positivity, the method of backward selection of variables was used. In this method, we considered a $P$ value of less than 0.05 to enter variable into the model and a $P$ value of less than 0.1 to exit the model. The significance level in all statistical tests was less than 0.05. It is notable that the missing data for variables were few (less than $2 \%$ ) and inconsiderable and they were deleted when analyzing.

\section{Results}

Out of a total of 2400 eligible individuals who enrolled in the study and completed the questionnaire, due to repeated codes or lack of questionnaires, finally, 2367 blood samples entered the final analysis. Table 1 shows the sample's main characteristics. The mean age of 2367 participants was 34.6 years with a standard deviation of 21.0; median age was 34 (range 2 to 95) years. Out of these, 1060 (44.8\%) were men, and 1472 (62.1\%) were married. A total of 1610 subjects (68\%) lived in villages. Pregnancy was registered in 31 out of $604(13.5 \%)$ married women from 10 to 49 years of age (Table 2).

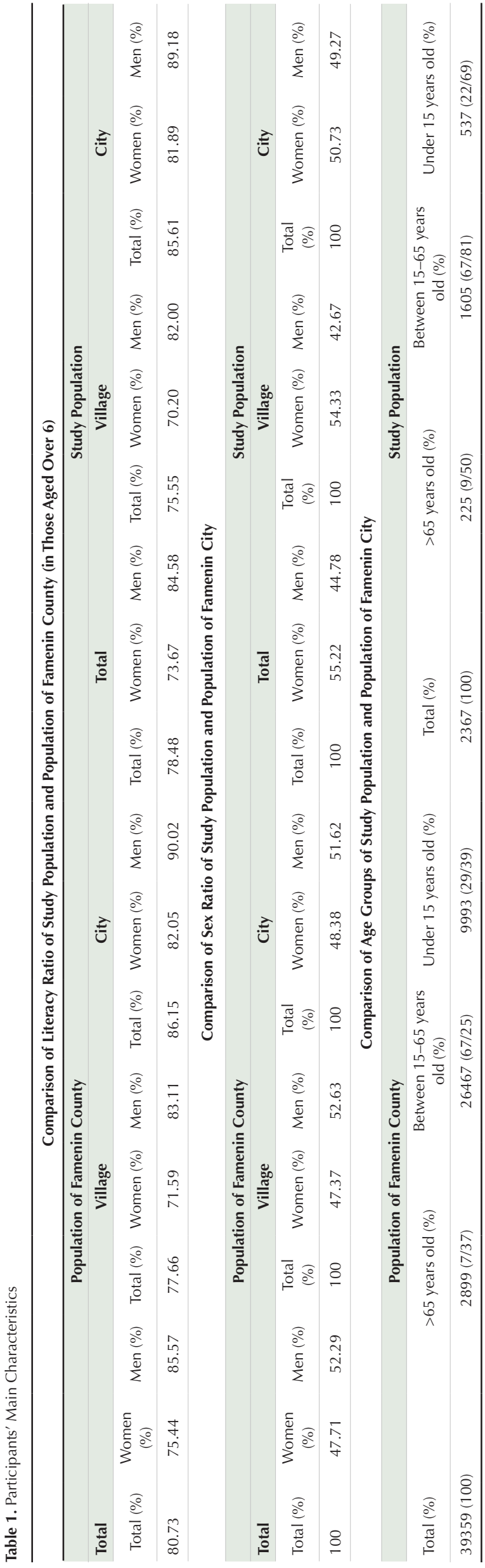


Table 2. Demographic Characteristics of Participants in Famenin Brucellosis Cohort Study

\begin{tabular}{|c|c|c|}
\hline Variable & Variable Levels & No. $(\%)$ \\
\hline \multirow{3}{*}{ Sex } & Male & $1060(44.8)$ \\
\hline & Female & 1307 (55.2) \\
\hline & Total & $2367(100)$ \\
\hline \multirow{3}{*}{$\begin{array}{l}\text { Pregnancy } \\
\text { (In married women, ages } \\
\text { 10-49) }\end{array}$} & Yes & $31(5.13)$ \\
\hline & No & $573(94.87)$ \\
\hline & Total & $604(100)$ \\
\hline \multirow{4}{*}{ Marital status } & Married & $1471(62.147)$ \\
\hline & Single & $894(37.769)$ \\
\hline & Missing data & $2(0.084)$ \\
\hline & Total & $2367(100)$ \\
\hline \multirow{7}{*}{ Education } & Illiterate & $635(26.830)$ \\
\hline & Elementary & $916(38.698)$ \\
\hline & Guidance & $399(16.856)$ \\
\hline & High school & $145(6.125)$ \\
\hline & Diploma & $194(8.196)$ \\
\hline & Super-diploma and higher & $78(3.295)$ \\
\hline & Total & $2367(100)$ \\
\hline \multirow{3}{*}{ Habitat } & City & 757 (31.98) \\
\hline & Village & $1610(68.02)$ \\
\hline & Total & $2367(100)$ \\
\hline \multirow{6}{*}{ Occupation } & Animal husbandry & $171(7.224)$ \\
\hline & Farmer & $258(10.900)$ \\
\hline & $\begin{array}{l}\text { Veterinarian, vaccinator, } \\
\text { slaughterhouse staff, } \\
\text { butcher, lab staff, dairy } \\
\text { sales, or cook }\end{array}$ & $8(0.336)$ \\
\hline & Housewife & $1006(45.501)$ \\
\hline & $\begin{array}{l}\text { Other (Students, children, } \\
\text { non-respondents, etc.) }\end{array}$ & $1053(44.487)$ \\
\hline & Total $* \mathrm{~A}$ & 22496 \\
\hline \multirow{5}{*}{ History of brucellosis } & Yes & $174(7.351)$ \\
\hline & No & $2182(92.184)$ \\
\hline & $\begin{array}{l}\text { A history of more than one } \\
\text { times }\end{array}$ & $1(0.042)$ \\
\hline & Missing data & $10(0.423)$ \\
\hline & Total & $2367(100)$ \\
\hline \multirow{7}{*}{ History of infection } & Forgotten & $4(2.281)$ \\
\hline & From 1976 to 1986 & $19(10.858)$ \\
\hline & From 1987 to 1996 & $62(35.428)$ \\
\hline & From 1997 to 2006 & $52(29.714)$ \\
\hline & From 2007 to 2016 & $35(20)$ \\
\hline & Missing data & $2(1.714)$ \\
\hline & Total & $174(100)$ \\
\hline \multirow{3}{*}{$\begin{array}{l}\text { Recurrence history (among } \\
\text { people with a history of } \\
\text { infection) }\end{array}$} & Yes & $12(6.89)$ \\
\hline & No & $162(93.11)$ \\
\hline & Total & $174(100)$ \\
\hline \multirow{3}{*}{$\begin{array}{l}\text { Number of relapses (among } \\
\text { people with recurrence } \\
\text { history) }\end{array}$} & One or two times & $8(66.666)$ \\
\hline & Missing data & $4(33.334)$ \\
\hline & Total & $12(100)$ \\
\hline \multirow{3}{*}{$\begin{array}{l}\text { Current treatment for } \\
\text { brucellosis (among people } \\
\text { with a history of infection) }\end{array}$} & Yes & $2(1.15)$ \\
\hline & No & $172(98.58)$ \\
\hline & Total & $174(100)$ \\
\hline \multirow{4}{*}{ Contact with livestock } & Yes & $785(33.164)$ \\
\hline & No & $1579(66.708)$ \\
\hline & Missing data & $3(0.128)$ \\
\hline & Total & $2367(100)$ \\
\hline \multirow{5}{*}{ Livestock species } & Cow & $206(26.424)$ \\
\hline & Sheep & $684(87.134)$ \\
\hline & Goat & $188(23.949)$ \\
\hline & Missing data & $5(0.637)$ \\
\hline & Total *B & 1083 \\
\hline
\end{tabular}

Table 2. Continued

\begin{tabular}{|c|c|c|}
\hline Variable & Variable Levels & No. $(\%)$ \\
\hline \multirow{10}{*}{$\begin{array}{l}\text { Type of contact with } \\
\text { livestock }\end{array}$} & Contact with aborted Fetus & $176(22.420)$ \\
\hline & Contact with live animals & $625(79.618)$ \\
\hline & $\begin{array}{l}\text { Contact with discharge } \\
\text { after delivery }\end{array}$ & $160(20.382)$ \\
\hline & Keeping livestock & $560(71.338)$ \\
\hline & Slaughtering the livestock & $73(9.229)$ \\
\hline & $\begin{array}{l}\text { Contact with meat and } \\
\text { organs }\end{array}$ & $144(18.334)$ \\
\hline & $\begin{array}{l}\text { Contact with carcasses and } \\
\text { livestock secretions after } \\
\text { slaughter }\end{array}$ & $79(10.064)$ \\
\hline & Milking livestock & $130(16.561)$ \\
\hline & Missing data & 3(0.382) \\
\hline & Total *C & 1950 \\
\hline \multirow{4}{*}{$\begin{array}{l}\text { Use of masks (people who } \\
\text { have contact with the } \\
\text { livestock) }\end{array}$} & Yes & $137(17.452)$ \\
\hline & No & $641(81.656)$ \\
\hline & Missing data & $7(0.892)$ \\
\hline & Total & $785(100)$ \\
\hline \multirow{3}{*}{ Using local dairy } & Yes & $2082(88.4)$ \\
\hline & No & $274(11.6)$ \\
\hline & Total & $2356(100)$ \\
\hline \multirow{10}{*}{ Local dairy type } & Milk & 1977 (95.5) \\
\hline & Skim milk & $326(15.7)$ \\
\hline & Cheese & $644(31)$ \\
\hline & Butter & 237 (91.6) \\
\hline & Cream & $200(17.6)$ \\
\hline & Curd & $366(17.96)$ \\
\hline & Colostrum & $47(2.3)$ \\
\hline & Traditional ice cream & $170(8.2)$ \\
\hline & Missing data & $2(0.096)$ \\
\hline & Total $* \mathrm{D}$ & 2082 \\
\hline \multirow{3}{*}{$\begin{array}{l}\text { Brucellosis infection in } \\
\text { family members during the } \\
\text { past two years }\end{array}$} & Yes & $51(2.2)$ \\
\hline & No & $2316(97.8)$ \\
\hline & Total & $2367(100)$ \\
\hline
\end{tabular}

${ }^{*}$ A: Due to more than one job for some people, the sum is more than $100 \%$. *B: Due to contact with more than one type of livestock, total percentages are more than $100 \%$

${ }^{*} \mathrm{C}$ : Due to several methods of contact with the livestock for an individual, the percentage is more than $100 \%$.

*D: Due to consumption of more than one type of dairy products, the sum of percentages is more than $100 \%$.

In the population studied, 1859 subjects $(78.5 \%)$ had a negative Wright test and in the remaining $508(21.5 \%)$ the Wright titers were between 1:20 and 1:5120. The prevalence with direct standardization based on age of the population is reported in Table 3. The ICC (Intra class correlation) obtained was less than 0.01 and we did not consider the design effect in prevalence calculation. However, in 156 participants, Wright titers were equal to or greater than 1:80 (Table 3). In total, the seroprevalence of brucellosis in the examined population of Famenin based on the serology titer of Wright test equal to or greater than $1: 80$ was $6.6 \%$ with a standard deviation of 0.005 and $95 \%$ confidence interval $5.62 \%-7.66 \%$. Table 4 shows that in the total population studied in Famenin (city and villages), 156 had a Wright test $\geq 1: 80$, 58 of them had $2 \mathrm{ME}$ titer $\geq 1: 40$ and in the rest of 98 
Table 3. Distribution of Wright Test Results Based on the Location of the Participants

\begin{tabular}{|c|c|c|c|c|c|c|c|}
\hline \multirow{2}{*}{ Wright titer* } & \multicolumn{2}{|c|}{ City } & \multicolumn{2}{|c|}{ Villages } & \multicolumn{3}{|c|}{ Total } \\
\hline & $\mathbf{F}$ & FP & $\mathbf{F}$ & FP & $\mathbf{F}$ & FP & DSP \\
\hline Negative & 565 & $74.6 \%$ & 1294 & $80.4 \%$ & 1859 & $78.5 \%$ & - \\
\hline $1: 20$ & 64 & $8.5 \%$ & 111 & $6.9 \%$ & 175 & $0.39 \%$ & 77.1 \\
\hline $1: 40$ & 76 & $10 \%$ & 101 & $6.3 \%$ & 177 & $7.47 \%$ & 39.0 \\
\hline 1:80 & 43 & $5.7 \%$ & 57 & $3.5 \%$ & 100 & $4.22 \%$ & 20.2 \\
\hline $1: 160$ & 9 & $1.2 \%$ & 28 & $1.7 \%$ & 37 & $1.60 \%$ & 14.8 \\
\hline $1: 320$ & 0 & $0 \%$ & 12 & $0.7 \%$ & 12 & $0.50 \%$ & 3.3 \\
\hline $1: 640$ & 0 & $0 \%$ & 5 & $0.3 \%$ & 5 & $0.21 \%$ & 2.0 \\
\hline 1:1280 & 0 & $0 \%$ & 0 & $0 \%$ & 0 & $0 \%$ & 0.0 \\
\hline $1: 2560$ & 0 & $0 \%$ & 1 & $0.1 \%$ & 1 & $0.04 \%$ & 0.4 \\
\hline $1: 5120$ & 0 & $0 \%$ & 1 & $0.1 \%$ & 1 & $0.04 \%$ & 0.4 \\
\hline Total & 757 & $100 \%$ & 1610 & $100 \%$ & 2367 & $100 \%$ & 157.2 \\
\hline
\end{tabular}

$\mathrm{F}$, frequency; DSP, direct standardized prevalence; $\mathrm{FP}$, frequency percent.

* The prevalence rate based on Wright titer $\geq 1: 20$ in all samples (2367) was $21.46 \%$ (confidence interval: $19.81 \%-23.10 \%$ ). The prevalence rate based on Wright titer $\geq 1: 80$ in all samples (2367) was $6.59 \%$ (confidence interval: $5.62 \%-7.66 \%$ ).

subjects, the $2 \mathrm{ME}$ titer was $\leq 1: 20$. The seroprevalence of brucellosis based on the $2 \mathrm{ME}$ titer of $\geq 1: 40$ was $37.2 \%$ when Wright titers were $\geq 1: 80$ and it was $2.4 \%$ among all 2367 subjects (Table 5). Besides, there was a significant difference between mean age $\pm S D$ of subjects with and without positive serology of Wright test $(42.2 \pm 19.8$ and $34.0 \pm 20.9$ years, respectively; $P<0.0001)$.

Table 6 shows that there was a correlation between occupation and positive serology of Wright test in the population studied in Famenin. Also, there was a significant relationship between history of contact with livestock as well as type of contact with livestock and positive serology in the population studied in Famenin.

Moreover, Table 7 shows the final model that was obtained with backward method in using multiple mixed effects logistic regression. The odds ratio of the disease was 3.74 (2.818-4.963), $(P<0.001)$; in other words, a history of brucellosis had a positive effect on Wright test results.

\section{Discussion}

In Iran, brucellosis is regarded as an endemic disease, and its most common cause is B. melitensis. ${ }^{4}$ As a result of the highly endemic epidemiological state, the accurate incidence of clinical brucellosis is not clear. ${ }^{16}$ The seroprevalence of brucellosis in our study according to the serologic titers of Wright test equal to or greater than $1: 80$ in the total sample was $6.6 \%$ and the seroprevalence of brucellosis based on $2 \mathrm{ME}$ titers $\geq 1: 40$ in subjects with positive Wright titers was $37.2 \%$ while in total, it was $2.4 \%$; it appears that the number of brucellosis cases was higher than those reported during the same year. In a study by Bokaie et al in Birjand among 422,106 individuals, the prevalence of brucellosis was 37 per 100000 people, which is equal to $0.03 \%$ and less than the prevalence we found. ${ }^{17}$

In our study, men constituted less than half of the sample, and the mean age was almost 35 years; in addition, $67.8 \%$ lived in rural areas. Brucellosis has the ability to infect individuals of all ages, but is more likely to be seen between the ages of 20 and 30 years. Also, the disease is seen in both genders with various predominance. ${ }^{4}$ In the study by Bokaie et al, brucellosis was more prevalent in men than women, and in rural parts than urban areas, with the age group of 20-40 years most frequently affected, which is similar to our findings. ${ }^{17}$ In a study by Poorhajibagher et al, out of 318 patients, $42(13.2 \%)$ had a Wright test equal to or greater than 1:80 and brucellosis was more common

Table 4. Distribution of Subjects According to Wright $(\geq 1.80)$ and $2 M E$ Titers

\begin{tabular}{|c|c|c|c|c|c|c|c|}
\hline \multirow{2}{*}{ 2ME Test* } & \multicolumn{6}{|c|}{ Wright Test } & \multirow{2}{*}{ Total } \\
\hline & $1 / 80$ & $1 / 160$ & $1 / 320$ & $1 / 640$ & $1 / 2560$ & $1 / 5120$ & \\
\hline Negative & 61 & 12 & 1 & 0 & 0 & 0 & 74 \\
\hline $1: 20$ & 17 & 7 & 0 & 0 & 0 & 0 & 24 \\
\hline $1: 40$ & 12 & 6 & 1 & 0 & 0 & 0 & 19 \\
\hline $1: 80$ & 10 & 7 & 6 & 1 & 0 & 0 & 24 \\
\hline $1: 160$ & 0 & 5 & 4 & 0 & 0 & 0 & 9 \\
\hline $1: 320$ & 0 & 0 & 0 & 1 & 1 & 0 & 2 \\
\hline $1: 640$ & 0 & 0 & 0 & 3 & 0 & 1 & 4 \\
\hline Total & 100 & 37 & 12 & 5 & 1 & 1 & 156 \\
\hline
\end{tabular}

*The prevalence of brucellosis in subjects with a $2 \mathrm{ME}$ titer $\geq 1: 20$ in all samples (156) was $52.66 \%$ (confidence interval: $44.64 \%-60.48 \%$ ) and the prevalence of brucellosis in subjects with a $2 \mathrm{ME}$ titer $\geq 1: 40$ in all samples (156) was $37.17 \%$ ( confidence interval: $29.50 \%-44.84 \%$ )

Table 5. Seroprevalence of Brucellosis Based on 2ME Titers in All Subjects (2367)

\begin{tabular}{lcc}
\hline 2ME Titers & $\begin{array}{c}\text { Number of } \\
\text { Subjects }\end{array}$ & Brucellosis Seroprevalence in A \\
\hline$\geq 1: 20$ & 82 & 3.46 (Confidence interval: $2.72 \%-4.20 \%)$ \\
$\geq 1: 40$ & 58 & 2.45 (Confidence interval: $1.82 \%-3.07 \%)$ \\
\hline
\end{tabular}

Table 6. Multiple Mixed Effect Logistic Regression Analysis in Subjects with a History of Brucellosis Associated with the Positive Wright Test

\begin{tabular}{lll}
\hline Variables & Odds Ratio $(\mathbf{9 5} \% \mathbf{C I})$ & $\boldsymbol{P}$ Value \\
\hline Constant factor & $0.289(0.183-0.456)$ & $<0.001$ \\
History of brucellosis & $3.74(2.818-4.963)$ & $<0.001$ \\
\hline
\end{tabular}


Table 7. Distribution of Risk Factors Associated with Wright Test Positivity

\begin{tabular}{|c|c|c|c|c|c|}
\hline \multirow{2}{*}{ Variables } & \multirow{2}{*}{ Subgroups } & \multicolumn{2}{|c|}{ Positive Wright Test } & \multirow{2}{*}{ Total $(\%)$} & \multirow{2}{*}{$P$ Value } \\
\hline & & Yes $(\%)$ & No $(\%)$ & & \\
\hline \multirow{2}{*}{ Contact with livestock } & Yes (\%) & $69(8.8)$ & $716(91.2)$ & $785(100)$ & \multirow{2}{*}{0.002} \\
\hline & No $(\%)$ & $87(5.5)$ & $1492(94.5)$ & $1579(100)$ & \\
\hline \multirow{9}{*}{$\begin{array}{l}\text { Type of contact with } \\
\text { livestock }\end{array}$} & Contact with aborted fetus & $24(13.6)$ & $152(86.42)$ & $176(100)$ & \multirow{9}{*}{$\begin{array}{c}\chi^{2}=18.8288 \\
P=0.009\end{array}$} \\
\hline & Contact with live animals & $53(8.5)$ & $572(91.5)$ & $625(100)$ & \\
\hline & Contact with discharge after delivery & $24(15)$ & $136(85)$ & $160(100)$ & \\
\hline & Keeping livestock & $49(8.8)$ & $511(91.3)$ & $560(100)$ & \\
\hline & Slaughter of livestock & $9(12.3)$ & $64(88.7)$ & $73(100)$ & \\
\hline & Contact with meat and organs & $20(13.9)$ & $124(86.1)$ & $144(100)$ & \\
\hline & Contact with carcasses and livestock secretions after slaughter & $9(12)$ & $66(88)$ & $75(100)$ & \\
\hline & Contact with aborted fetus & $14(10.8)$ & $116(89.2)$ & $130(100)$ & \\
\hline & Contact with live animals & $104(10.4)$ & $1741(89.6)$ & $1943(100)$ & \\
\hline \multirow{3}{*}{ Livestock species } & Sheep and goat & $88(10.1)$ & $784(89.9)$ & $206(100)$ & \multirow{3}{*}{$P=0.094$} \\
\hline & Cow & $13(6.3)$ & $193(93.7)$ & $188(100)$ & \\
\hline & Total & $101(9.4)$ & 977 (90.6) & 1078 (100) & \\
\hline \multirow{2}{*}{$\begin{array}{l}\text { Use of masks and gloves in } \\
\text { contact with the livestock }\end{array}$} & Yes $(\%)$ & $45(32.8)$ & $92(67.2)$ & $137(100)$ & \multirow{2}{*}{$P=0.202$} \\
\hline & No $(\%)$ & $147(22.9)$ & $494(77.1)$ & $641(100)$ & \\
\hline \multirow{2}{*}{$\begin{array}{l}\text { Consumption of } \\
\text { unpasteurized dairy products }\end{array}$} & Yes $(\%)$ & $439(21.1)$ & 1643(78.9) & $2082(100)$ & \multirow{2}{*}{$P=0.790$} \\
\hline & No $(\%)$ & $64(23.7)$ & $209(76.3)$ & $274(100)$ & \\
\hline \multirow{9}{*}{$\begin{array}{l}\text { Consumption of different } \\
\text { types of dairy products }\end{array}$} & Milk & $134(6.8)$ & $1843(93.25)$ & $1977(100)$ & \multirow{9}{*}{$\begin{array}{c}\chi^{2}=12.2977 \\
P=0.091\end{array}$} \\
\hline & Skim milk & $22(6.7)$ & $304(93.3)$ & $326(100)$ & \\
\hline & Cheese & $42(6.5)$ & $602(93.5)$ & $644(100)$ & \\
\hline & Butter & $14(5.9)$ & $223(94.1)$ & $237(100)$ & \\
\hline & Cream & $13(6.5)$ & $187(93.5)$ & $200(100)$ & \\
\hline & Curd & $38(10.4)$ & $328(89.6)$ & $366(100)$ & \\
\hline & Colostrum & $1(2.1)$ & $46(97.9)$ & $47(100)$ & \\
\hline & Traditional ice cream & $6(3.5)$ & $164(96.5)$ & $170(100)$ & \\
\hline & Total & $270(6.8)$ & $3699(93.2)$ & $3969(100)$ & \\
\hline \multirow{5}{*}{ Occupation } & Rancher & $21(12.3)$ & $150(87.7)$ & $171(100)$ & \multirow{5}{*}{$\begin{array}{c}\chi^{2}=21.6169 \\
P<0.001\end{array}$} \\
\hline & Farmer & 30 (11.6) & $228(88.4)$ & $258(100)$ & \\
\hline & Housewife & $78(7.8)$ & $928(92.2)$ & $1006(100)$ & \\
\hline & Other & $44(.05)$ & $841(95.0)$ & $885(100)$ & \\
\hline & Total & $173(7.5)$ & 2149 (92.5) & $2322(100)$ & \\
\hline
\end{tabular}

in men compared to women. The sample size in their study was small and, in addition, people with symptoms suspected of brucellosis had been referred, whereas our study was based on the general population of Famenin. ${ }^{15}$ In a study by Hashemi et al, $77 \%$ of patients were living in villages. ${ }^{18}$ Also, in a study by Hajia et al, the participants were aged 15 to 110 years and $61.2 \%$ were men and $38.8 \%$ were women. ${ }^{19}$ In a study by Keramat et al, $59.9 \%$ were men, the mean age was 40.69 years, and 64\% of the patients lived in villages. ${ }^{20}$ In another study by Hajia and colleagues at Sina Hospital in Hamadan, 67.9\% of brucellosis patients lived in rural and $32.1 \%$ lived in urban areas. ${ }^{21}$ Also, in a study by Eini and colleagues between 2005 and 2010 in Hamadan, 43.5\% of the subjects were men with a mean age of 40.84 years and $72.2 \%$ of the patients lived in villages. ${ }^{22}$ In various studies, ${ }^{18-22}$ the mean age and mean rate of disease were higher in men than women and most patients lived in villages, which is similar to the results of this study.

However, in a study by Ranjbar and colleagues on 228 brucellosis patients in Hamadan between 1999 and 2001, 107 (48.6\%) of patients were men, the average age of patients was 36.35 years and $50 \%$ were rural residents. ${ }^{23}$ Another study by Hashemi and colleagues in Hamadan on 219 brucellosis patients between 2008 and 2010 showed that $48.4 \%$ (106) of the patients were men and 113 $(51.6 \%)$ were women with an average age of 39.67 years, of whom $73(33.3 \%)$ were rural residents. ${ }^{24}$ In recent studies, brucellosis cases were reported more frequently in women than men, and cases who lived in urban areas were more than or equal to cases in rural areas. ${ }^{23,24}$ This is in contrast to our study, and this difference may be due to the fact that analysis was applied only on patients who were admitted to the hospitals, while our study was in the general population; also another important reason may be the transformation of rural areas to urban areas based on 
changing country divisions over time.

One of the reasons for the spread of brucellosis in our country is the poorer hygiene among some villagers and farmers; also, agriculture and animal husbandry are very mixed with the rural and nomadic lives of our people. Still, the tent of livestock is set up next to the room and tent of their owners and as soon as new domestic animals are born, young children embrace and stroke them. In some regions of Iran, congestion of plants, high rainfall, lack of sunlight, as well as unhealthy practices in process of providing milk and meat cause the spread of brucellosis. Another common cause of brucellosis in Iran is the consumption of unpasteurized milk from animals infected by Brucella, especially colostrum or concentrated milk, which is consumed raw immediately after delivery as a complete meal. Unpasteurized dairy products are still extensively bought in villages and even in cities, and this is another factor in the spread of this disease even among educated people in the community. In our study, we observed a significant relationship between positive brucellosis serology and contact with livestock, use of masks and gloves in contact with the livestock, animal husbandry, farming and previous infection of brucellosis.

In a study by Hasanjani Roshan et al, 55.9\% of the patients were male, $75.8 \%$ were from rural environments and $45.9 \%$ had a history of unpasteurized dairy consumption. There was a significant association between the incidence of brucellosis and occupation and consumption of dairy products as two important risk factors. ${ }^{25}$ In our study, there was no significant relationship between unpasteurized dairy consumption and brucellosis, which might be due to the fact that our study was performed on the general population in Famenin. Also, in a study by Eini et al, 39.7\% had contact with livestock and 49.6\% consumed unpasteurized dairy. ${ }^{22}$ These studies indicate that unpasteurized dairy consumption and exposure to livestock are among the major risk factors for brucellosis.

The risk of brucellosis transmission can be reduced by practicing hygiene, avoiding contact with the tissues of affected animals, or avoiding non-pasteurized milk. During abortion and shortly after that, by releasing highly infectious uterine secretions, livestock with brucellosis could contaminate the environment, grounds and pastures and can spread the infection to other animals and humans. Also respiratory transmission to humans has been reported through contaminated suspended particles in air and dust of stalls. ${ }^{6}$ In our study, we observed a significant relationship between contact with livestock and the occurrence of brucellosis. Also, people who deal with animals are more likely to acquire the brucellosis infection. ${ }^{6,26}$ In this study, there was a significant relationship between high risk jobs (animal husbandry, agriculture) and positive brucellosis serology. Subjects with positive Wright serology had significantly more frequent contact with livestock, but there was no significant relationship between positive brucellosis serology and dairy consumption. In a study by Nematollahi et al, the rate of brucellosis recurrence was higher in females, as well as in subjects older than 50 years, and those with a history of consuming unpasteurized dairy products, but not in those people who did not have history of contact with animals. ${ }^{4}$

One of the main strengths of this study was that it is the first study of its kind to enroll a large sample size of participants in urban and rural areas in Iran. Second, we have conducted this large seroprevalence study using survey approach in the general population, in contrast to other studies which were done on patients. Accordingly, our study provides external validity and generalizability of seroprevalence findings to general population for the first time. However, the weaknesses of the study were non-registration of clinical manifestations and the examination of participants with signs and symptoms of brucellosis. Therefore, in Famenin population, the actual rate of people with brucellosis should be higher than the reported annual incidence. Yet, we know that the best way to finally win the battle against human brucellosis is control and subsequent eradication of animal brucellosis. In near future, we are going to extend our study to the seroprevalence of brucellosis among livestock in Famenin.

In conclusion, based on the results of this study, the seroprevalence of brucellosis in the population of Famenin was $6.6 \%$ based on positive Wright test and $2.4 \%$ based on positive $2 \mathrm{ME}$ test. The chance of being positive for the Wright test was 3.74 times higher in people with a history of brucellosis than those who did not have any history of disease. Contact with livestock, livestock husbandry, farming, and rural residence were risk factors for higher possibility of brucellosis. The results of our study will be used as basic data for the Famenin Brucellosis Cohort Study, which is needed for preventive interventions and measures against brucellosis in Famenin.

\section{Authors' Contribution}

All authors have approved the manuscript. FK, MK and MA has established first idea, data analysis and drafted manuscript. SB, JA, AM, ZS, MYA and MB helped to design and conduct the study. All authors have had significant contribution in data gathering, Sampling, manuscript drafting, interpretation and critical revision of manuscript and data analysis.

\section{Conflict of Interest Disclosures}

Authors have no conflicts of interests to declare.

\section{Ethical Statement}

This study was approved by the Committee on Ethics of Hamadan University of Medical Sciences. We revived written informed consent forms from participants or parents/guardians by educated interviewers to participate in the study.

\section{Availability of Data and Material}

The datasets used and analyses during the current study could be obtained from the corresponding author by a documentary email.

\section{Funding}

The study was funded by Vice-chancellor for Research and 
Technology, Hamadan University of Medical Sciences (Grant No. 9504222003). This granting body has not been assigned for publication fee.

\section{Acknowledgements}

We are grateful to Mr. Seyyed Jalal Batahee, Dr. Mehdi Dinari, Dr. Saeed Khakizadeh, Mr. Mehdi Hosseini, and all the staff members of Famenin health center who contributed to subject referral, completion of the questionnaires and blood sampling of the participants in Famenin. Also, we thank the staff of the core facility of Hamadan University of Medical Sciences who carried out the serological tests, as well as Ms. Samira Karami and Mr. Ali Saadatmand, experts from the Brucellosis Research Center who performed the necessary coordination during the course of the project.

\section{References}

1. Corbel MJ. Brucellosis in humans and animals: World Health Organization; 2006. Available from: https://www.who.int/csr/ resources/publications/Brucellosis.pdf.

2. Salata RA, Goldman L, Ausiello D, editors. Brucellosis. In: Cecil Medicine. 23rd ed. Philadelphia: Saunders; 2008: 224851.

3. Gul HC, Erdem H. Brucellosis (Brucella species). Mandell, Douglas, and Bennett's Principles and Practice of Infectious Diseases. 8th ed. Philadelphia: Elsevier Saunders; 2015:25849.e3.

4. Nematollahi S, Ayubi E, Karami M, Khazaei S, Shojaeian M, Zamani R, et al. Epidemiological characteristics of human brucellosis in Hamadan province during 2009-2015: results from the National Notifiable Diseases Surveillance System. Int J Infect Dis. 2017;61:56-61. doi: 10.1016/j.ijid.2017.06.002.

5. Keramat F, Majzobi MM, Poorolajal J, Ghane ZZ, Adabi M. Seroprevalence of brucellosis in human immunodeficiency virus infected patients in Hamadan, Iran. Osong Public Health Res Perspect. 2017;8(4):282-288. doi: 10.24171/j. phrp.2017.8.4.09.

6. Zeinali M, Shirzadi M, Sharifian J. National Guideline for Brucellosis Control. Tehran: Ministry of Health and Medical Education; 2009:10-7.

7. Afsharpaiman S, Mamishi S. Brucellosis: review of clinical and laboratory features and therapeutic regimens in 44 children. Acta Medica Iranica. 2008;46(6):489-94.

8. Salari M, Khalili M, Hassanpour G. Selected epidemiological features of human brucellosis in Yazd, Islamic Republic of Iran. 1993-1998. 2003. East Mediterr Health J. 2003;9(56):1054-60.

9. Erfanian M, Nouzadi S, Mohsen S, Jarahi L. Evaluation of Diagnostic Sensitivity of Wright, Coombs Wright and 2-Mercapto Ethanol in Diagnosis of Brucellosis. Evidence Based Care. 2013;2(4):69-74.

10. Pabuccuoglu O, Ecemis T, El S, Coskun A, Akcali S, Sanlidag T. Evaluation of serological tests for diagnosis of brucellosis. Jpn J Infect Dis. 2011;64(4):272-6.

11. Gómez MC, Nieto JA, Rosa C, Geijo P, Escribano MA, Munoz A, et al. Evaluation of seven tests for diagnosis of human brucellosis in an area where the disease is endemic. Clin Vaccine Immunol. 2008;15(6):1031-3. doi: 10.1128/ CVI.00424-07

12. Mert A, Ozaras R, Tabak F, Bilir M, Yilmaz M, Kurt C, et al.
The sensitivity and specificity of Brucella agglutination tests. Diagn Microbiol Infect Dis. 2003;46(4):241-3. doi: 10.1016/ s0732-8893(03)00081-6.

13. Najafi N, Davoodi L, Fazli M, Davoudi Badabi A, Yazdani Charati J. Diagnostic Value of Elisa Versus Wright in Human Brucellosis with Positive PCR. J Mazandaran Univ Med Sci. 2014;23(1):21-8.

14. Seyed NS, Erfanian TM. Evaluation of diagnostic validity of Wright's serologic test in Brucellosis. J Birjand Univ Med Sci. 2009;16(3):28-32

15. Poorhajibagher $M$, Pagheh A, Nasrollahi $M$, Mesgarian F, Badiee F, Ajami A. The evaluation of seroprevalence of brucellosis in patients refering to health care center of Gonbad Kavoos, 2009-11. J Mazandaran Univ Med Sci. 2012;22(90):82-6.

16. Bonfoh B, Kasymbekov J, Dürr S, Toktobaev N, Doherr MG, Schueth T, et al. Representative seroprevalences of brucellosis in humans and livestock in Kyrgyzstan. Ecohealth. 2012;9(2):132-8. doi: 10.1007/s10393-011-0722-x.

17. Bokaie S, Sharifi L, Alizadeh H. Epidemiological survey of brucellosis in human and animals in Birjand, east of Iran. J Anim Vet Adv. 2008;7(4):460-3.

18. Hashemi SH, Keramat F, Ranjbar M, Mamani M, Farzam A, Jamal-Omidi S. Osteoarticular complications of brucellosis in Hamedan, an endemic area in the west of Iran. Int J Infect Dis. 2007;11(6):496-500. doi: 10.1016/j.ijid.2007.01.008.

19. Hajia M, Rahbar M, Keramat F. Epidemiological, clinical, diagnostic and treatment aspects of hospitalized brucellosis patients in Hamadan. Jpn J Infect Dis. 2017;70(3):235-238. doi: 10.7883/yoken.JJID.2016.133.

20. Keramat F, Ranjbar M, Mamani M, Hashemi SH, Zeraati F. A comparative trial of three therapeutic regimens: ciprofloxacinrifampin, ciprofloxacin-doxycycline and doxycycline-rifampin in the treatment of brucellosis. Trop Doct. 2009;39(4):207-10. doi: 10.1258/td.2009.090030.

21. Hajia M, Keramat F. Study On the rate of brucellosis relaps efficiency different treatment protocols in among hospitalized patient in educational hospital of Hamadan. Journal Mil Med. 2003;5(3):195-9.

22. Eini P, Keramat F, Hasanzadehhoseinabadi M. Epidemiologic, clinical and laboratory findings of patients with brucellosis in Hamadan, west of Iran. J Res Health Sci. 2012;12(2):105-8.

23. Ranjbar M, Keramat F, Mamani M, Kia AR, Hashemi SH, Nojomi M. Comparison between doxycycline-rifampinamikacin and doxycycline-rifampin regimens in the treatment of brucellosis. Int J Infect Dis. 2007;11(2):152-6. doi: 10.1016/j.ijid.2005.11.007.

24. Hashemi SH, Gachkar L, Keramat F, Mamani M, Hajilooi M, Janbakhsh A, et al. Comparison of doxycycline-streptomycin, doxycycline-rifampin, and ofloxacin-rifampin in the treatment of brucellosis: a randomized clinical trial. Int J Infect Dis. 2012;16(4):e247-51. doi: 10.1016/j.ijid.2011.12.003.

25. Roushan MRH, Ebrahimpour S, Moulana Z. Different clinical presentations of brucellosis. Jundishapur J Microbiol. 2016;9(4):e33765. doi: 10.5812/jjm.33765.

26. Gul HC, Bennett JE, Dolin R. Brucellosis (Brucella species). Bennett JE, Dolin R, Blaser MJ, eds. Principles and Practice of Infectious Diseases. 8th ed. Philadelphia: Churchill Livingstone; 2015:2584-9. 